\title{
Transferosomes: Unique vesicular carriers for effective transdermal delivery
}

\author{
Rakesh Pahwa ${ }^{1 *}$, Shweta Pal ${ }^{1}$, Kamal Saroha ${ }^{1}$, Parul Waliyan ${ }^{1}$, Manish Kumar ${ }^{2}$ \\ ${ }^{1}$ Institute of Pharmaceutical Sciences, Kurukshetra University, Kurukshetra, India. \\ ${ }^{2} \mathrm{MM}$ College of Pharmacy, Maharishi Markandeshwar (Deemed to be University), Ambala, India.
}

\section{ARTICLE INFO \\ Received on: 09/10/2020 \\ Accepted on: 03/02/2021 \\ Available online: 05/05/2021}

Key words:

Transdermal delivery, ultradeformable vesicles, transferosomes, selfassembled, improved skin permeation, enhanced bioavailability.

\begin{abstract}
The utilization of vesicular carriers has recently emerged as a promising strategy to reduce the hindrance associated with the stratum corneum. Transferosomes are also recognized as ultradeformable lipids and elastic liposomes attract tremendous attention toward dermal delivery. They are predominantly used to treat various incidences of chronic skin disorders and also convenient for targeted as well as controlled delivery to manage patient compliance. These self-assembled nanocarriers are capable of molding themselves according to the pore size of the stratum corneum. Transferosomes may consist of edge activators (specialized surfactants), phospholipids, buffering agent, etc. The effect of edge activators and their concentration confers a desirable elasticity to assembled vesicles. Elastic liposomes are capable of optimizing the solubilization of the drug, effective drug loading capability, and permeability of therapeutic molecules. Transferosomes as nanocarriers exhibit advanced reflections and a versatile platform for successful transdermal applications. These unique nanocarriers also exhibit superior elasticity as well as penetration performance. These systems are considered secure with efficient delivery strategies for pharmaceutically as well as cosmeceutically active chemical moieties. Recent scientific observations indicating the importance of ultradeformable liposomes have shown reproducible and efficient permeation of active drugs. This manuscript covers the current research advancements along with informative reports addressing the important issues and usefulness of prospective transferosomes with a better bioavailability profile.
\end{abstract}

\section{INTRODUCTION}

Globally, nanotechnology is accepted as one of the leading vistas for improved therapeutic profiles of various drugs (Sadaf and Ajazuddin, 2010). Nanoformulations also reveal salient attributes, including enhancement in drug solubility, bioavailability, prevention from physicochemical degradation, as well as toxicity, and also overcoming drug leakage (Gangwar et al., 2012; Sadaf and Ajazuddin, 2010). Biocompatible vesicular systems have great potential for the administration of various active molecules to improve their clinical efficacy. It can also deliver several drugs for therapeutic, biochemical, and cosmetic benefits (Hussain et al., 2017; Rai et al., 2017). Various classes of "somes" have been

${ }^{*}$ Corresponding Author

Rakesh Pahwa, Institute of Pharmaceutical Sciences, Kurukshetra University, Kurukshetra,India.rakesh_pahwa2407@yahoo.co.in introduced in nanotechnology and all "somes" are specifically utilized for their pivotal characteristics. Transferosomes are considered an improved form of liposomes and have numerous names - ultradeformable liposomes, deformable liposomes, flexible liposomes, ultraflexible liposomes, and elastic liposomes (Hussain et al., 2017). Transferosomes are distinct from liposomes because they have more elasticity and flexibility provided by the edge activator which modulates the vesicle according to the skin pores and reaches the systemic circulation (Jain et al., 2017b). Ultraflexible liposomes have also shown the ability to shrink the vesicle through channels and again reform its original diameter after crossing the biological membrane and ultimately reaching the systemic circulation (Jain et al., 2017b; Sawant et al., 2017; Srivastava et al., 2017). These vesicles respond to external stress by rapid shape modification with low energy (Podili and Firoz, 2014). Basically, it is specialized for their stretchable behavior which is attributed by the edge activators (Sala et al., 2016). These activators reduce the interfacial tension and consequently augment 
the shrinking ability of the carrier system. Vesicles can carry small, moderate, as well as highly, molecular hydrophobic, hydrophilic or amphiphilic chemical moiety in a better stable single vesicle system (Walve et al., 2011).

Transferosomes are accessible forms applied to nonocclusive skin and release the drug which depicts improved pharmacological effects, as well as minimum patient incompliance (Kumar et al., 2012; Walve et al., 2011). Furthermore, they can prevent hepatic first-pass metabolism and ultimately provide better pharmacokinetic efficacy (Eldhose et al., 2016; Pardhan et al., 2013; Sarangi et al., 2018). Also, ultradeformable vesicles can easily adopt herbal extracts and synthetic actives and deliver intact moiety without drug leakage in targeted sites (Kulkarni et al., 2011; Saraf et al., 2011). These vesicular carriers emerged as significant systems for the treatment of varied skin diseases by overcoming the penetration-limiting barriers and, consequently, enhancing the efficacy with substantial clinical benefits. These carriers also presented new dimensions for transdermal delivery of actives in a proficient and fascinating manner. Confocal scanning laser microscopy has been used for the investigation of the penetration mechanism of transferosomes (Gangwar et al., 2012). The transferosomal drug delivery form is widely used to treat various types of diseases successfully and achieve better biocompatibility, bioavailability, cost-effectiveness, and patient compliance (Eldhose et al., 2016; Kulkarni et al., 2011).

Owing to the elastic attributes of transferosomes, these ultraflexible vesicular systems can effortlessly cross the physiological-limiting barriers and deliver the drug efficiently to its active site. In addition, the prime advantage of utilizing transferosomes as a nanocarrier includes triumphant delivery of macromolecules through the skin employing a non-invasive route, hence subsequently improving the patient's compliance. Also, they successfully deliver insulin, corticosteroids, high weighted protein and peptides, interferons, anti-cancerous drugs, anesthetics, nonsteroidal anti-inflammatory drugs, and various herbal active moieties (Chaudhary et al., 2016; Chauhan et al., 2018a; Eldhose et al., 2016; Jain et al., 2017a; Kaurav et al., 2016; Kulkarni et al., 2011; Mota et al., 2017; Rady et al., 2018; Saraf et al., 2011). This review depicts the growth and benefits of transferosomes in a vesicular family for providing a better therapeutic profile and utility. In this manuscript, various important aspects, advantages, preparation methods, and salient applications of transferosomes have also been explored.

\section{Major advantages}

Various advantages are elaborated as follows (Hussain et al., 2017; Podili and Firoz, 2014; Rai et al., 2017; Walve et al., 2011):

- High entrapment efficacy.

- High efficiency to modify according to pore size, therefore better penetration ability.

- Deliver smaller, as well as larger, weighted molecules without any measurable loss.

- Depot drug, releases drug slowly and gradually in a controlled manner.

- Utilized for systemic as well as topical application.
- Avoid first-pass metabolism, physicochemical degradation, and provide protection to encapsulated drug.

- Site specificity and increased bioavailability.

- Simple procedure of formulation and evaluation.

- Biocompatible and biodegradable.

- Provide patient compliance and also suitable for unconscious patients.

\section{Limitations}

Transferosomes have crucial features in nanodrug delivery; however, some of the drawbacks are as follows (Hussain et al., 2017; Kumar et al., 2012):

- Sometimes, chemical formulations may become unstable due to their oxidative degradation.

- Reorganization of transferosomes is also associated with the purity of natural phospholipids.

- Higher cost associated with the expensive manufacturing procedure is essential for the fabrication of transferosomes as compared with other conventional gel preparations.

- It is very difficult to utilize the finest properties of a system for targeted therapy without cautious and rational formulation design.

\section{Preparation methodology}

Transferosomes are preferably prepared by two methods: the rotary evaporation sonication and vortexing-sonication methods, as shown in Figure 1.

The rotary evaporation sonication process comprises the dissolution of phosphatidylcholine along with the edge activator in a mixture of chloroform and methanol and is further followed by organic solvent removal utilizing the rotary evaporator under reduced pressure at a suitable temperature. While revolving the container at room temperature, the film deposited gets hydrated with therapeutic agent solution in an appropriate aqueous phase. The vesicles produced are allowed for swelling, followed by sonication

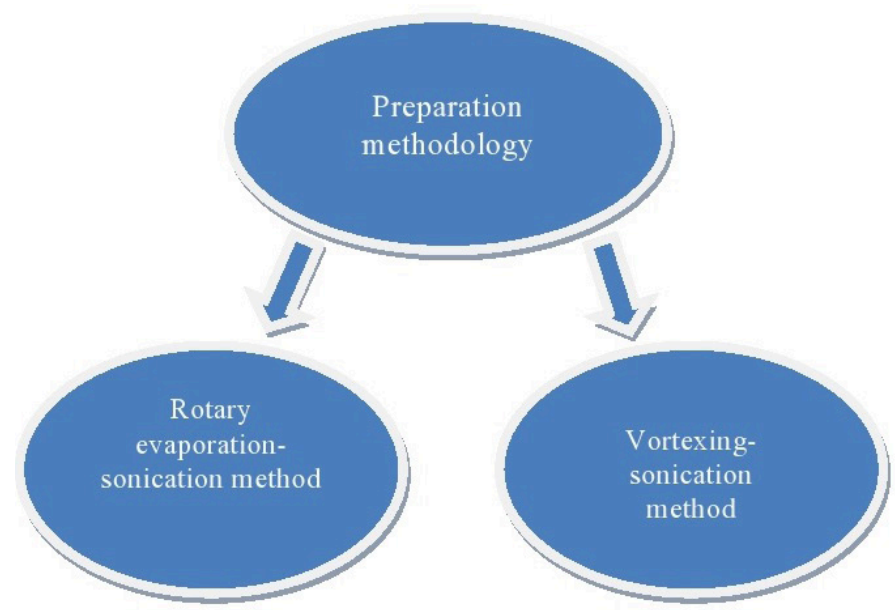

Figure 1. Preparation methods of transferosomes. 
using a bath sonicator. Subsequently, the vesicle extrusion occurs through the polycarbonate membrane and the resulting vesicles are stored at an appropriate temperature for further use. In the vortexing sonication process, phosphatidylcholine and edge activators in addition to the therapeutic molecule are blended in a suitable phosphate buffer and then vortexed appropriately to achieve a milky suspension. The suspension is properly sonicated, followed by extrusion via a polycarbonate filter (Kumar et al., 2012). The chemical compositions for the formulation of ultradeformable vesicles may be similar in both the methods (Duangjit et al., 2013; Kumar et al., 2012). Ultradeformable transferosomes can be obtained successfully by utilizing these methods and stored in an appropriate environmental condition for long duration stability.

\section{Evaluation}

The overall investigation and characterization aspects include various crucial parameters such as vesicle size, zeta potential, polydispersity index (El-feky et al., 2019; Preeti et al., 2014), transmission electron microscopy (Chauhan et al., 2018a; Lei et al., 2013), scanning electron microscopy (Badr-eldin et al., 2016; Lei et al., 2013), differential scanning calorimetry (Elkomy et al., 2017; Tosato et al., 2018), confocal laser scanning microscopy (Podili and Firoz, 2014; Walve et al., 2011 ), etc. The vesicle diameter can be determined using photon correlation spectroscopy or dynamic light scattering method. Both polydispersity index and zeta potential can also be assessed by using this technique. The measurement of the zeta potential can present a prediction concerning the stability features. For morphological investigation of nano-sized vesicles, scanning electron microscopy and transmission electron microscopy are commonly employed. Differential scanning calorimetry is also comprehensively utilized in practice to inspect the crystallinity and polymorphic performance of the ingredients. The elasticity index of the vesicles can be estimated by extrusion measurement. Skin penetration study is generally accomplished using confocal laser scanning microscopy (Chauhan et al., 2018a; El-feky et al., 2019; Elkomy et al., 2017; Lei et al., 2013; Podili and Firoz, 2014).

These evaluation parameters contribute to a systematic practice to comprehend the effectiveness and achievement of drug loading capability, drug release profile, and ultimately therapeutic potential of ultraflexible liposomal formulation. The evaluation of transferosomes is essential to understand the relationship among various important components, as well as processing factors involved during the preparation of nanometric optimized formulations. Suitable characterization of ultraflexible nanocarriers is also necessary to control the product eminence and stability features, in addition to release kinetics. In vitro drug release, entrapment efficacy, penetration ability, flexibility measurement, turbidity measurement, drug content, occlusion effect, etc. can also be evaluated for transferosomal preparations (Kumar et al., 2012; Sachan et al., 2013).

\section{Therapeutic applications}

Ultradeformable vesicles can be widely utilized as effective carriers for the delivery of various drugs. They have shown better skin permeation for achieving promising pharmacokinetic profiles. Therapeutic applications utilizing these effective carriers are mentioned as follows:

- Proteins and peptides' drug delivery: Selfregulating transferosomes have been studied to deliver proteins and peptides (Cevc 2003; Cevc et al., 1998; Paul, 1998; Yang, 2002).

- NSAIDs: Transferosomes are potentially employed to deliver anti-inflammatory and anti-pyretic drugs successfully, e.g., corticosteroids (Cevc et al., 1997), ketoprofen (Cevc et al., 2008), diclofenac sodium (Ghanbarzadeh et al., 2013), etc.

- Anti-hypertensive drugs: Hypertension is a disease condition which can be treated by incorporating drug in transferosomal preparations, e.g., propranolol hydrochloride (Mishra et al., 2007), valsartan (Ahad et al., 2012), and nifedipine (Manvir et al., 2012), with better therapeutic effects.

- Anti-fungal drugs: Growth of microbes can be retarded by transferosomal applications, e.g., metronidazole (Vanić et al., 2013), itraconazole (Alomrani et al., 2014), miconazole nitrate (Pandit et al., 2014), amphotericin B (Singodia et al., 2010), and terbinafine (Ghannoum et al., 2011, 2012).

- Local anesthetics: Local anesthetic nanocarriers are explored to improve the action of drugs, e.g., butamben (Cereda et al., 2013), and butamben and benzocaine (Maestrelli et al., 2010).

- Anti-androgenic alopecia: Finasteride transferosomal vesicles have been investigated for the management of androgenetic alopecia (Ahmed and Rizq, 2018).

- Anti-gout agents: The elastic liposomal formulation of colchicine revealed great potential in the treatment of acute gout (Singh et al., 2009).

- Anti-obestiy agents: Transferosomes of nanoemodin has been investigated for anti-obesity ( $\mathrm{Lu}$ et al., 2014).

- Anti-cancer drugs: Transferosomes, nanovesicular systems have shown capability to deliver anticancerous drugs effectively, e.g., celecoxib (Bragagni et al., 2012), cisplatin (Gupta, 2011), and vincristine (Lu et al., 2007).

- Anti-migraine drugs: Neurological disorder has been examined by the sustained delivery of antimigraine drug rizatriptan (Garg et al., 2008).

\section{Applications in cosmetics}

The demand of cosmetics rises worldwide progressively in order to intensify the appearance and avoidance of skin damage. Cosmeceutical products enhance beauty aspects and also confer various therapeutic benefits. Applications of transferosomes in the avenue of cosmetics and cosmeceuticals are enlisted as follows and are shown in Figure 2. 


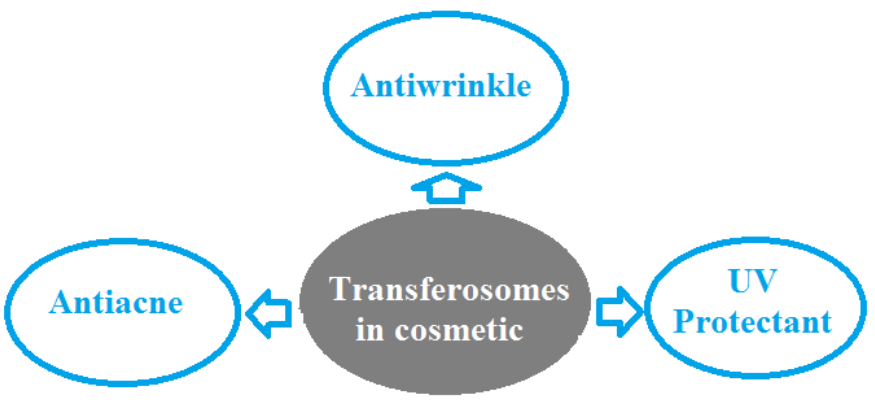

Figure 2. Schematic representation of transferosomes' applications in cosmetic technology.
- Anti-wrinkle agents: Anti-wrinkle effects have been investigated by incorporating Curcuma longa (Saraf et al., 2011) and rosemary extracts (Ezzat et al., 2016) into transferosomal vesicles.

- UV protectant: Formulation of transferosomal gel has been investigated for UV radiation skin damage, e.g., C. longa (Kaur et al., 2013) and quercetin (Liu et al., 2013).

- Anti-acne agents: Topical delivery of transferosomes has potential to reduce acne, e.g., clindamycin (Gupta et al., 2017) and Vitamin C (Vasanth et al., 2020).

Table 1. Transdermal delivery of active moieties by ultradeformable liposomes.

\begin{tabular}{|c|c|c|c|}
\hline S. No. & Drug & Major findings & Reference(s) \\
\hline 1. & Lornoxicam & Superior entrapment efficacy and penetration & (Tawfeek et al., 2020) \\
\hline 2. & Ammonium glycyrrhizate & Potential anti-inflammatory therapy & (Barone et al., 2020) \\
\hline 3. & Tamsulosin & Enhanced permeation and bioavailability & (Almehmady et al., 2020) \\
\hline 4. & Retinyl Palmitate & Penetration increased & (Rodriguez et al., 2020) \\
\hline 5. & Adapalene & Improved in vitro skin delivery & (Vasanth et al., 2020) \\
\hline 6. & Methotrexate & Increased penetrating ability in inflammatory condition & (Bahramizadeh et al., 2019) \\
\hline 7. & Colchicine & Higher efficacy, rapid onset, and longer duration of action & (El-Feky et al.,2019) \\
\hline 8. & Felodipine & Increased permeation & (Kamani et al., 2019) \\
\hline 9. & Cilnidipine & Improved bioavailability & (Khatoon et al., 2019) \\
\hline 10 & Iloperidone & Better permeation and sustained drug delivery & (Londhe et al., 2019) \\
\hline 11. & Natamycin & Improved topical ocular pharmacotherapy & (Janga et al., 2019) \\
\hline $12 .$. & Lidocaine & Improved permeation and stability of drug & (Omar et al., 2019) \\
\hline 13. & Genistein & Reduced oxidative damage & (Langasco et al., 2019) \\
\hline 14. & Chlorine aluminum phthalocyanine & Increased skin permeability & (Escobar et al., 2018) \\
\hline 15. & Glycyrrhizic acid & Prolonged release of drug & (Chauhan et al., 2018b) \\
\hline 16. & Raloxifene hydrochloride & Increased flexibility and stability & (Joshi et al., 2018) \\
\hline 17. & 3-O-cetyl ascorbic acid and tocopherol acetate & Improved bioavailability & (Fushimi et al., 2018) \\
\hline 18. & Felodipine & Enhanced drug bioavailability & (Kassem et al., 2018) \\
\hline 19. & Resveratrol & Higher efficacy & (Tosato et al., 2018) \\
\hline 20. & Trolamine salicylate & Higher permeability & (Makhmalzadeh et al., 2018) \\
\hline 21. & Curcumin & Increased penetration for treatment of breast cancer & (Abdel-Hafez et al., 2018) \\
\hline 22. & Epigallocatechin-3-gallate (EGCG) and hyaluronic acid & Higher skin permeation and deposition of EGCG & (Avadhani et al., 2017) \\
\hline 23. & Sertaconazole nitrate & Superior antifungal activity & (Abdellatif et al., 2017) \\
\hline 24. & Loratadine & Increased bioavailability & (Elkomy et al., 2017) \\
\hline 25. & Risperidone & Improved transdermal permeation & (Das et al., 2017) \\
\hline 26. & Sildenafil citrate & Extended absorption and higher bioavailability & (Badr-eldin et al., 2016) \\
\hline 27. & Pentoxifylline & Increased bioavailability & (Al shuwaili et al., 2016) \\
\hline 28. & Fluconazole & Increased drug efficacy & (Tejaswini et al., 2016) \\
\hline 29. & Timolol maleate & Increased bioavailability & (Morsi et al., 2016) \\
\hline 30. & Tramadol HCl & Better penetration of the drug & (Singh et al., 2016) \\
\hline 31. & 5-fluorouracil & Biocompatible and better penetration & (Zhang et al., 2015) \\
\hline 32. & Repaglinide & $\begin{array}{l}\text { Increased entrapment efficacy, maximum drug release, } \\
\text { and better permeation }\end{array}$ & (Laxmi et al., 2015) \\
\hline 33. & Diclofenac sodium & Good entrapment efficiency and stability & (Sultana et al., 2015) \\
\hline 34. & Papaverine hydrochloride & Enhanced drug delivery & (Ali et al., 2015) \\
\hline 35. & Raloxifene hydrochloride & Higher drug permeation capability & (Mahmood et al., 2014) \\
\hline 36. & Celecoxib & Better entrapment & (Preeti et al., 2014) \\
\hline
\end{tabular}




\begin{tabular}{|c|c|c|c|}
\hline S. No. & Drug & Major findings & Reference(s) \\
\hline 37. & Ciprofloxacin & Increased drug permeation across ear skin & (Al-mahallawi et al., 2014) \\
\hline 38. & Piroxicam & Excellent release and permeation of drug & (Shaji and Lal, 2014) \\
\hline 39. & Buspirone $\mathrm{HCl}$ & Increased drug permeation & (Shamma et al., 2013) \\
\hline 40. & Tacrolimus & Enhanced skin permeation & (Lei et al., 2013) \\
\hline 41. & Resveratrol & Increased penetration & (Scognamiglio et al., 2013) \\
\hline 42. & Nystatin & Prolonged release and improved site specificity & (Abdallah et al., 2013) \\
\hline 43. & Insulin & Higher stability over enzymatic degradation & (Malakar et al., 2012) \\
\hline 44. & Ketoconazole & Higher in vitro drug release & (Rajan et al., 2012) \\
\hline 45. & Ketorolac tromethamine & Excellent loading efficiency & (Nava et al., 2011) \\
\hline 46. & Colchicine & Increased skin permeation and deposition & (Singh et al., 2010) \\
\hline 47. & Curcumin & Better permeation & (Patel et al., 2009) \\
\hline 48. & Methotrexate & $\begin{array}{l}\text { Frequency of dosing reduced, improved efficacy, and } \\
\text { patient compliance }\end{array}$ & (Vanaja et al., 2008) \\
\hline 49. & $\alpha$-tocopherol & Improved in vitro skin delivery & (Gallarate et al., 2006) \\
\hline 50. & Methotrexate & Improved in vitro skin delivery & (Trotta et al., 2004) \\
\hline 51. & Estradiol & Improved in vitro skin delivery & (El Maghraby et al., 2000) \\
\hline 52. & Insulin & $\begin{array}{l}\text { Better penetration and reduced chances of drug } \\
\text { degradation }\end{array}$ & (Cevc et al., 1998) \\
\hline
\end{tabular}

Intensive research has been carried out on numerous moieties by utilizing ultradeformable liposomes. Table 1 shows the various transferosomal research reports of scientific community across the globe with impressive and encouraging observations.

\section{CONCLUSION}

The transdermal route has been the most preferable route of drug administration because of its unique and versatile characteristics. However, the major concern for transdermal delivery is impermeable the stratum corneum which creates an obstacle for the entry of drugs completely. Therefore, the transferosomal system emphasizes the effective delivery of hydrophilic and hydrophobic drugs along with amphiphilic compounds in a successful manner. Transferosomes are suitable and an excellent approach owing to their reduction in dose frequency, improved efficacy, enhanced loading capacity, and increased topical applications along with better stability aspects. Transferosomes have favorable and encouraging potential for the transportation of active drugs with site-specificity and also utilized in various cosmetic strategies. Several impediments are still remaining to be resolved concerning oxidative degradation, purity, and retention property. Hence, potential improvement in the process requires special considerations and technological advancements. Additionally, to facilitate future prospects of these talented nanocarriers, progress in synergistic potential of ingredients and active molecules also needs to be investigated across the globe. It is also highlighted that sophisticated research based on persuasive preclinical and clinical studies are required to gather the information essential to ascertain the safety aspect of challenging drugs ahead of industrial scale-up. Improvements are still needed on scientific vistas for the development of innovative transferosomes which will probably focus on the superior therapeutic regimens utilizing more advanced, promising, and well-organized new strategies. It is also important to explore new pharmaceutical excipients with additional features for minimizing the existing drawbacks associated with transferosomes. In future, industrial pharmaceutical companies may explore new opportunities for significant developmental characteristics of transferosomes with appropriately tailored features.

\section{AUTHOR CONTRIBUTIONS}

All authors made substantial contributions to conception and design, acquisition of data, or analysis and interpretation of data; took part in drafting the article or revising it critically for important intellectual content; agreed to submit to the current journal; gave final approval of the version to be published; and agree to be accountable for all aspects of the work. All the authors are eligible to be an author as per the international committee of medical journal editors (ICMJE) requirements/guidelines.

\section{FUNDING}

There is no funding to report.

\section{CONFLICTS OF INTEREST}

The authors report no financial or any other conflicts of interest in this work.

\section{ETHICAL APPROVALS}

Not applicable.

\section{PUBLISHER'S NOTE}

This journal remains neutral with regard to jurisdictional claims in published institutional affiliation.

\section{REFERENCES}

Abdallah MH. Transferosomes as a transdermal drug delivery system for enhancement the antifungal activity of nystatin. Int $\mathrm{J}$ Pharm Pharm Sci, 2013; 5(4):560-7.

Abdel-Hafez SM, Hathout RM, Sammour OA. Curcuminloaded ultradeformable nanovesicles as a potential delivery system for breast cancer therapy. Colloid Surf B, 2018; 167(8):63-72.

Abdellatif MM, Khalil IA, Khalil MAF. Sertaconazole nitrate loaded nanovesicular systems for targeting skin fungal infection: in-vitro, ex-vivo and evaluation. Int J Pharm, 2017; 527(1-2): 1-11. 
Ahad A, Aqil M, Kohli K, Sultana Y, Mujeeb M, Ali A. Formulation and optimization of nanotransfersomes using experimental design technique for accentuated transdermal delivery of valsartan. Nanomedicine, 2012; 8(2):237-49.

Ahmed OA, Rizq WY. Finasteride nano-transferosomal gel formula for management of androgenetic alopecia: ex-vivo investigational approach. Drug Des Devel Ther, 2018; 12(1):2259-65.

Al shuwaili AH, Bazigha K, Rasool A, Abdulrasool AA. Optimization of elastic transfersomes formulations for transdermal delivery of pentoxifylline. Eur J Pharm Biopharm, 2016; 102(2):101-14.

Ali MFM, Salem HF, Abdelmohsen HF, Attia SK. Preparation and clinical evaluation of nanotransferosomes for treatment of erectile dysfunction. Drug Des Devel Ther, 2015; 9(4):2431-47.

Al-mahallawi AM, Shoukri RA. Nano-transferosomal ciprofloxacin loaded vesicles for non-invasive trans-tympanico to topical delivery. In-vitro optimization, ex-vivo permeation studies and in-vivo assessment. Int J Pharm, 2014; 472(1):304-14.

Almehmady AM, Elsisi AM. Development, optimization, and evaluation of tamsulosin nanotransfersomes to enhance its permeation and bioavailability. J Drug Deliv Sci Technol, 2020; 57:101667

Alomrani AH, Shazly GA, Amara AA, Badran MM. Itraconazole hydroxypropyl- $\beta$-cyclodextrin loaded deformable liposomes: in-vitro skin penetration studies and antifungal efficacy using Candida albicans as model. Colloid Surf B, 2014; 121(2):74-81.

Avadhani KS, Manikkath J, Tiwari M, Chandrasekhar M, Godavarthi A, Vidya SM, R Hariharapura RC, Kalthur G, Udupa N, Mutalik S. Skin delivery of epigallocatechin-3-gallate (EGCG) and hyaluronic acid loaded nano-transfersomes for antioxidant and anti-aging effects in UV radiation induced skin damage. Drug Deliv, 2017; 24(1):61-74.

Badr-eldin SM, Ahmed O. Optimized nano-transfersomal films for enhanced sildenafil citrate transdermal delivery: ex-vivo and in-vivo evaluation. Drug Des Devel Ther, 2016; 10(1):1323-33.

Bahramizadeh M, Bahramizadeh M, Kiafar B, Jafarian AH, NikpoorAR, HatamipourM, Esmaily H, RezaeemehrZ, Golmohammadzadeh S, Moosavian SA, Jafari MR. Development, characterization and evaluation of topical methotrexate-entrapped deformable liposome on imiquimodinduced psoriasis in a mouse model. Int J Pharm, 2019; 569:118623.

Barone A, Cristiano MC, Cilurzo F, Locatelli M, Iannotta D, Marzio LD, Celia C, Paolino D. Ammonium glycyrrhizate skin delivery from ultradeformable liposomes: a novel use as an anti-inflammatory agent in topical drug delivery. Colloids Surf B, 2020; 193:111152.

Bragagni M, Mennini N, Maestrelli F, Cirri M, Mura P. Comparative study of liposomes, transfersomes and ethosomes as carriers for improving topical delivery of celecoxib. Drug Deliv, 2012; 19(7):354 61

Cereda CM, Franz-Montan M, Da Silva CM. Transdermal delivery of butamben using elastic and conventional liposomes. J Liposome Res, 2013; 23(3):228-34.

Cevc G, Blume G, Schatzein A. Transfersomes-mediated transepidermal delivery improves the region-specificity and biological activity of corticosteroids in-vivo. J Control Release, 1997; 45(2):211-26.

Cevc G, Gebauer D, Stieber J, Schatzlein A, Blume G. Ultraflexible vesicles, transfersomes, have an extremely low pore penetration resistance and transport therapeutic amounts of insulin across the intact mammalian skin. Biochim Biophys Acta, 1998; 1368(2):201-15.

Cevc G, Mazagaream S, Rother M. Preclinical characterization of NSAIDs in ultradeformable carriers or conventional topical gels. Int J Pharm, 2008; 360(1-2):29-39.

Cevc G. Transdermal drug delivery of insulin with ultradeformable carriers. Clin Pharmacokinet, 2003; 42(5):461-74.

Chaudhari Y, Dharashivkar S, Palkar P, Chaudhari M, Ruhatiya G, Patil M, Gaikwad M. Formulation and evaluation of transferosomal cream of acriflavine. Int Res J Pharm, 2016; 7(8):75-8.

Chauhan P, Kumar TB. Herbal novel drug delivery system and transferosome. J Drug Deliv Ther, 2018a; 8(3):162-8.
Chauhan S, Gulati N, Nagaich U. Fabrication and evaluation of ultra deformable vesicles for atopic dermatitis as topical delivery. Int J Polym Mater Polym Biomater, 2018b; 68(5):266-77.

Das B, Sen SO, Maji R, Nayak AK, Sen KK. Transferosomal gel for transdermal delivery of risperidone: formulation optimization and exvivo permeation. J Drug Deliv Sci Technol, 2017; 38(3):59-71.

Duangjit S, Opanasopit P, Rojarata T, Obata Y, Oniki Y, Takayama $\mathrm{K}$, Ngawhirunpat T. The role of deformable liposome characteristics on skin permeability of meloxicam: optimal transferosome as transdermal delivery carriers. Open Conf Proc J, 2013; 4(2):87-92.

Eldhose MP, Mathew F, Mathew NJ. Transferosomes - a review. Int J Pharm Pharm Sci, 2016; 6(4):436-52.

El-Feky GS, El-Naa MM, Mahmoud AA. Flexible nano-sized lipid vesicles for the transdermal delivery of colchicine; in-vitro/in-vivo investigation. J Drug Deliv Sci Technol, 2019; 45(1):24-34.

Elkomy MH, El Menshawe SF, Abou-taleb A, Elkarmalawy H. Loratadine bioavailability via buccal transferosomal gel: formulation, statistical optimization, in-vitro/in-vivo characterization, and pharmacokinetics in human volunteers. Drug Deliv, 2017; 24(1):781-91.

El Maghraby GMM, Williams AC, Barry BW. Oestradiol skin delivery from ultradeformable liposomes: refinement of surfactant concentration. Int J Pharm, 2000; 196(5):63-74.

Escobar P, Vera AM, Neira LF, Velásquez AO, Carreño $\mathrm{H}$ Photodynamic therapy using ultradeformable liposomes loaded with chlorine aluminum phthalocyanine against L. (V.) braziliensis experimental models. Exp Parasitol, 2018; 194(2):45-52.

Ezzat SM, Salama MM, Elmeshad AN, Teaima MH, Rashad LA. HPLC-DAD-MS/MS profiling of standardized rosemary extract and enhancement of its anti-wrinkle activity by encapsulation in elastic nanovesicles. Arch Pharm Res, 2016; 39(7):912-25.

Fushimi T, Uchino T, Miyazaki Y, Hatta I, Asano M, Fujino H, Suzuki R, Fujimori S, Kamiya D, Kagawa Y. Development of phospholipid nanoparticles encapsulating 3-O-cetyl ascorbic acid and tocopherol acetate (TA-Cassome) for improving their skin accumulation. Int J Phar, 2018; 548(1):192-205.

Gallarate M, Chirio D, Trotta M, Carlotti ME. Deformable liposomes as topical formulations containing $\alpha$-tocopherol. J Dispers Sci Technol, 2006; 27(3):703-13.

Gangwar M, Singh R, Goel RK, Nath G. Recent advances in various emerging vesicular systems: an overview. Asian Pac J Trop Biomed, 2012; 2(2):S1176-88

Garg T, Jain S, Singh HP, Sharma A, Tiwary AK. Elastic liposomal formulation for sustained delivery of antimigraine drug: in-vitro characterization and biological evaluation. Drug Dev Ind Pharm, 2008; 34(10):1100-10.

Ghanbarzadeh S, Arami S. Enhanced transdermal delivery of diclofenac sodium via conventional liposomes, ethosomes, and transfersomes. Biomed Res Int, 2013; 2013:1-7.

Ghannoum M, Isham N, Henry W, Henry W, Yurdakul S. Evaluation of the morphological effects of TDT 067 (terbinafine in transfersome) and conventional terbinafine on dermatophyte hyphae invitro and in-vivo. Antimicrob Agents Chemother, 2012; 56(5):2530-34.

Ghannoum M, Isham N, Herbert J, Henry W, Yurdakul S Activity of TDT 067 (terbinafine in transferosomes) against agents of onychomycosis as determined by minimum inhibitory and fungicidal concentration. J Clin Microbiol, 2011; 49(5):1716-20.

Gupta M, Prajapati RN, Irchhaiya R, Singh N, Prajapati SK. Novel clindamycin loaded transferosomes formulation for effective management of acne. World J Pharm Res, 2017; 6(6):765-73.

Gupta V. Reduction in cisplatin genotoxicity (micronucleus formulation) in non target cells of mice by protransferosomes gel formulation used for management of cutaneous squamous cell carcinoma. Acta Pharm, 2011; 61(1):63-71.

Hussain A, Singh S, Sharma D, Webster TJ, Shafaat K, Faruk A Elastic liposomes as novel carriers: recent advances in drug delivery. Int J Nanomedicine, 2017; 12(4):5087-108. 
Jain P, Rahi P, Pandey V, Aasti S, Soni V. Nanostructure lipid carriers: a modish contrivance to overcome the ultraviolet effects. Egypt J Basic Appl Sci, 2017a; 4(2):89-100.

Jain S, Patel N, Shah M, Khatri P, Vora N. Recent advances in lipid-based vesicles and particulate carriers for topical and transdermal application. J Pharm Sci, 2017b; 106(2): 423-45.

Janga KY, Tatke A, Dudhipala N, Balguri SP, Ibrahim MM, Maria DN, Jablonski MM, Majumdar S. Gellan gum based sol-to-gel transforming system of natamycin transfersomes improves topical ocular delivery. J Pharmacol Exp Ther, 2019; 370(3):814-22.

Joshi A, Kulkarni R, Chaudhari R. In-vitro and Ex-vivo evaluation of raloxifene hydrochloride delivery using nanotransfersome based formulations. J Drug Deliv Sci Technol, 2018; 45(2):151-8.

Kamani P, Kinjal P, Kapadia R, Sawant K. Phospholipid based ultra-deformable nanovesicular gel for transcutaneous application: QbD based optimization, characterization and pharmacodynamic profiling. J Drug Deliv Sci Technol, 2019; 51(6):152-63.

Kassem MA, Aboul-Einien MH, El Taweel MM. Dry gel containing optimized felodipine-loaded transferosomes: a promising transdermal delivery system to enhance drug bioavailability. AAPS Pharmsci, 2018; 19(5):2155-73.

Kaur CD, Saraf S. Topical vesicular formulations of Curcuma longa extract on recuperating the ultraviolet radiation-damaged skin. J Cosmet Dermatol, 2011; 10(4):260-65.

Kaurav M, Minz S, Sahu K, Kumar M, Madan J, Pandey RS. Nanoparticulate mediated transcutaneous immunization: myth or reality. Nanomedicine-Nanotechnol, 2016; 12(4):1063-81.

Khatoon K, Rizwanullah M, Amin S, Mir SR, Akhter S. Cilnidipine loaded transfersomes for transdermal application: formulation optimization, in-vitro and in-vivo study. J Drug Deliv Sci Technol, 2019; 54(3):1-35.

Kulkarni PR, Yadav JD, Vaidya AK, Gandhi PP. Transferosome: an emerging tool for transdermal drug delivery. Int J Pharm Sci Res, 2011; 2(4):735-41.

Kumar A, Pathak K, Bali V. Ultra-adaptable nanovesicular system: a carrier for systemic delivery of therapeutic agents. Drug Discov Today, 2012; 17(21-22):1233-41.

Langasco R, Fancello S, Rassu G, Cossu M, Cavalli R, Galleri G, Giunchedi P, Migheli R Gavini E. Increasing protective activity of genistein by loading into transfersomes: a new potential adjuvant in the oxidative stress-related neurodegenerative diseases. Phytomedicine, 2019; 18(1):30488-94.

Laxmi M, Zaffarauddin Md, Kuchana V. Design and characterization of transferosomal gel of repaglinide. Int J Pharm, 2015; 6(1):38-42.

Lei W, Yu C, Lin H, Zhou X. Development of tacrolimus-loaded transferosomes for deeper skin penetration enhancement and therapeutics effect improvement in-vivo. Asian J Pharm Sci, 2013; 8(4):336-45.

Liu D, Hu H, Lin Z. Quercetin deformable liposome: preparation and efficacy against ultraviolet $\mathrm{B}$ induced skin damages in-vitro and in-vivo. J Photochem Photobiol B, 2013; 127(2):8-17.

Londhe VY, Bhasin B. Transdermal lipid vesicular delivery of iloperidone: formulation, in-vitro and in-vivo evaluation. Colloid Surf B, 2019; 183(4):1-7.

Lu K, Xie S, Han S, Zhang J, Chang X, Chao J, Huang Q, Yuan Q, Lin H, Xu L, Shen C, Tan M, Qu S, Wang C, Song X. Preparation of a nano emodin transfersome and study on its anti-obesity mechanism in adipose tissue of diet-induced obese rats. J Transl Med, 2014; 12(1):2-14.

Lu Y, Hou SX, Zhang LK, Li Y, He JY, Guo DD. Transdermal and lymph targeting transfersomes of vincristine. Acta Pharm Sin, 2007 42(10):1097-101.

Maestrelli F, González-Rodríguez ML, Rabasco AM, Ghelardini C, Mura P. New "drug-in cyclodextrin-in deformable liposomes" formulations to improve the therapeutic efficacy of local anesthetics. Int J Pharm, 2010; 395(1-2):222-31.
Mahmood S, Uttam T, Mandal K. Experimental design and optimization of raloxifene hydrochloride loaded nanotransfersomes for transdermal application. Int J Nanomedicine, 2014; 9(3):4331-46.

Makhmalzadeh BS, Salimi A, Nazarian A, Esfahani G. Formulation characterization and in-vivo/ ex-vivo evaluation of trolamine salicylate-loaded transferosome as transdermal drug delivery carriers. Int J Pharm Sci Res, 2018; 9(2):3725-31.

Malakar J, Sen SO, Nayak AK, Sen KK. Formulation, optimization and evaluation of transferosomal gel for transdermal insulin delivery. Saudi Pharm J, 2012; 20(7):355-63.

Manvir A, Rana AC, Seth N, Bala R. Elastic liposome mediated transdermal delivery of an anti-hypertensive agent: nifedipine. J Drug Deliv Ther, 2012; 2(5):55-60.

Mishra D, Garg M, Dubey V, Jain S, Jain NK. Elastic liposomes mediated transdermal delivery of an anti-hypertensive agent: propranolol hydrochloride. J Pharm Sci, 2007; 96(1):145-55.

Morsi NM, Aboelwafa AA, Dawaud MHS. Improved bioavailability of timolol maleate via transdermal transferosomal gel: statistical, optimization, characterization and pharmacokinetics assessment J Adv Res, 2016; 7(3):691-01.

Mota AH, Rijo PI, Molpeceres J, Reis CP. Broad overview of engineering of functional nanosystems for skin delivery. Int J Pharm, 2017; 553(2):710-28.

Nava G, Elizabeth P, Luis M, Néstor M, Quintanar D, Ganem A. Formulation and in-vitro, ex-vivo and in-vivo evaluation of elastic liposomes for transdermal delivery of ketorolac tromethamine. Pharmaceutics, 2011; 3(4):954-70.

Omar MM, Hasan OA, Elsisi AM. Preparation and optimization of lidocaine transferosomal gel containing permeation enhancers: a promising approach for enhancement of skin permeation. Int J Nanomedicines, 2019; 14(2):1551-62.

Pandit J, Garg M, Jain NK. Miconazole nitrate bearing ultraflexible liposomes for the treatment of fungal infection. J Liposome Res, 2014; 24(2):163-9.

Pardhan M, Singh D, Singh MR. Novel colloidal carriers for psoriasis: current issues, mechanistic insight and novel delivery approaches. J Control Release, 2013; 170(3):380-95.

Patel R, Singh SK, Singh S, Sheth NR, Gendle R. Development and characterization of curcumin loaded transfersome for transdermal delivery. J Pharm Sci Res, 2009; 4(1):71-80.

Paul A. Transdermal immunization with an integral membrane component, gap junction protein, by means of ultradeformable drug carriers, transferosomes. Vaccines. 1998; 16(2):188-95.

Podili C, Firoz S. A review on transferosome for transdermal drug delivery. J Glob Trends Pharm Sci, 2014; 5(4):2118-27.

Preeti, Kumar MS. Development of celecoxib transfersomal gel for the treatment of rheumatoid arthritis. Indian J Pharm Biol Res, 2014; 2(2):7-13.

Rady M, Iman Gomaa I, Afifi N, Mahmoud AK. Dermal delivery of Fe-chlorophyllin via ultradeformable nanovesicles for photodynamic therapy in melanoma animal model. Int J Pharm, 2018; 548(1):480-90.

Rai S, Pandey V, Rai G. Transferosomes as versatile and flexible nano-vesicular carriers in skin cancer therapy: the state of the art. Nano Rev Exp, 2017; 8(1):1325708.

Rajan R, Vasudevan D. Effect of permeation enhancers on the penetration mechanism of transfersomal gel of ketoconazole. J Adv Pharm Technol Res, 2012; 3(2):112-6.

Rodriguez EP, Mareno MC, Fernandez BB, Gonzalez J, Campos FF. Epidermal delivery of retinyl palmitate loaded transfersomes: penetration and biodistribution studies. Pharmaceutics, 2020; 12(2):112.

Sachan R, Soniya PT, Singh V, Singh G, Yagi S, Patel C, Gupta A. Drug carrier transferosome: a novel tool for transdermal drug delivery system. Int J Res Dev Pharm Life Sci, 2013; 2(2):309-16.

Sadaf S, Ajazuddin. Application of novel drug delivery system for herbal formulation. Fitoterapia, 2010; 81(4):680-89. 
Sala M, Elaissari A, Fessi H. Advances in psoriasis physiopathology and treatments: up to date of mechanistic insights and perspectives of novel therapies based on innovative skin drug delivery systems. J Control Release, 2016; 239(5):182-02.

Saraf S, Jeswani G, Kaur CD, Saraf S. Development of novel herbal cosmetic cream with curcuma longa extract loaded transferosomes for antiwrinkle effect. Afr J Pharm Pharmacol, 2011; 5(8):1054-62.

Sarangi M, Padhi S. Novel herbal drug delivery system: an overview. Arch Med Health Sci, 2018; 6(4):171-79.

Sawant B, Khan T. Recent advances in delivery of antifungal agents for therapeutic management of candidiasis. Biomed Pharmacother. 2017; 96(5):1478-90.

Scognamiglio I, Stefano DD, Campani V, Mayol L, Cornuccio R, Fabbrocini G, Ayala F, Rotonda MIL, Rosa GD. Nanocarriers for topical administration of resveratrol: a comparative study. Int J Pharm, 2013; 440(6): 179-87.

Shaji J, Lal M. Preparation, optimization and evaluation of transferosomal formulation for enhanced transdermal delivery of a Cox-2 inhibitor. Int J Pharm Pharm Sci, 2014; 6(1):467-77.

Shamma RN, Elsa I. Transfersomal lyophilized gel of buspirone $\mathrm{HCl}$ : formulation, evaluation and statistical optimization. J Liposome Res, 2013; 23(3):244-54.

Singh H, Utreja P, Tiwary A, Jain S. Elastic liposomal formulation for sustained delivery of colchicine: in-vitro characterization and in-vivo evaluation of antigout activity. AAPS J, 2009; 11(1):54-64.

Singh HP, Tiwary AK, Jain SP. Preparation and in-vitro, in-vivo characterization of elastic liposomes encapsulating cyclodextrin-colchicine complexes for topical delivery of colchicines. Yakugaku Zasshi, 2010; 130(3):397-07.

Singh S, Vardhan H, Kotla N, Maddiboyina B, Sharma D, Webster TJ. The role of surfactants in the formulation of elastic liposomal gels containing a synthetic opioid analgesic. Int J Nanomedicine, 2016; 11(1):1475-82.

Singodia D, Gupta GK, Verma A, Singh V, Shukla P, Misra P, Sundar S, Dube A, Mishra PR. Development and performance evaluation of amphotericin B transfersomes against resistant and sensitive clinical isolates of visceral leishmaniasis. J Biomed Nanotechnol, 2010; 6(3):293-02.

Srivastava S, Singh D, Patel S, Parihar AKS, Singh MR. Novel carters and targeted approaches: way out for rheumatoid arthritis quandrum. J Drug Deliv Sci Technol, 2017; 40(3):125-35.

Sultana SS, Sailaja AK. Formulation and evaluation of diclofenac sodium transferosomes using different surfactants by thin film hydration method. Der Pharmacia Lett, 2015; 7(11):43-53.
Tawfeek HM, Abdellatif AAH, Abdel-Aleem JA, Hassan YA, Fathalla D. Transfersomal gel nanocarriers for enhancement the permeation of lornoxicam. J Drug Deliv Sci Tech, 2020; 56:101540.

Tejaswini K, Swapna S, Babu AM, Bakshi V. Formulation and evaluation of fluconazole loaded transfersome gel. Int J Sci Res Methodol, 2016; 3(3):1-14.

Tosato MG, Julie V, Girón M, Martin AA, Tippavajhala VK, Mele M, Dicelio L. Comparative study of transdermal drug delivery systems of resveratrol: high efficiency of deformable liposomes. Mater Sci Eng C, 2018; 90(2):356-64.

Trotta M, Peira E, Carlotti ME, Gallarate M. Deformable liposomes for dermal administration of methotrexate. Int J Pharm, 2004 270(4):119-25.

Vanaja K, Rani S, Sacchidananda S. Formulation and clinical evaluation of ultradeformable liposomes in the topical treatment of psoriasis. Clin Res Regul Aff, 2008; 25(1):41-2.

Vanić Ž, Hafner A, Bego M, Škalko-Basnet N. Characterization of various deformable liposomes with metronidazole. Drug Dev Ind Pharm, 2013; 39(3):481-88.

Vasanth S, Dubey A, Ravi GS, Lewis SA, Ghate VM, El-Zahaby SA, Hebbar S. Development and investigation of vitamin C-enriched adapalene-loaded transfersome gel: a collegial approach for the treatment of acne vulgaris. AAPS PharmSciTech, 2020;21(2):61.

Walve JR, Bakliwal SR, Rane BR, Pawar SP. Transferosome: surrogated carriers for transdermal drug delivery system. Int J Appl Biol Pharm, 2011; 2(1):204-13.

Yang TZ. Phospholipid deformable vesicles for buccal delivery of insulin. Chem Pharm Bull, 2002; 50(6):749-53

Zhang Z, Wang X, Chen X, Wo Y, Zhang Y, Ewelina B. 5-Fluorouracil-loaded transfersome as theranostics in dermal tumor of hypertrophic scar tissue. J Nanomater, 2015; 143(4):455-62.

How to cite this article:

Pahwa R, Pal S, Saroha K, Waliyan P, Kumar M. Transferosomes: Unique vesicular carriers for effective transdermal delivery. J Appl Pharm Sci, 2021; 11(05):001-008. 